\title{
Comparative assessment of technologies and machines using nonparametric criteria
}

\author{
Dmitry Petukhov ${ }^{1, *}$, Vitaly Tarkivsky ${ }^{1}$, Svetlana Sviridova $^{1}$, and Sergey Semizorov ${ }^{2}$ \\ ${ }^{1}$ Novokubansk Affiliate of Russian Research Instittute of Information and Feasibility Study on \\ Engineering Support of Agribusiness the Federal State Bugetary Scientific Institution, 352243, 15, \\ Krasnaya Str., Krasnodar Region, Novokubansk, Russia \\ ${ }^{2}$ Northern Trans-Ural State Agricultural University, 625003, 7, Respublika Str., Tyumen, Russia
}

\begin{abstract}
Methods for comprehensive assessment of technologies and machines are presented using nonparametric criteria for a single quantitative indicator in the form of a specific number, the value of which allows to choose the most preferable option. Examples of comparative assessments of agricultural technologies and sowing units using generalized assessment criteria are given. The software "Nonparametric selection" is described.
\end{abstract}

\section{Introduction}

The strategy of scientific and technological development of the Russian Federation provides for the transition to a highly productive and environmentally friendly agricultural sector, which today cannot be implemented without the introduction of resource-saving technologies for the cultivation and harvesting of agricultural crops and their technical reequipment with high-performance equipment of a new generation.

With the introduction of technologies and the modernization of the machine and tractor fleet, an urgent question arises about the acquisition of new samples of agricultural machinery from the point of view of the different organizational structure of economic entities and various natural and climatic conditions. Moreover, the main problem for agricultural producers is a comparative assessment and selection of the most effective technologies and technical means.

In modern conditions of economic relations, it is important to conduct an economic assessment of agricultural units in order to identify the most preferred technologies and determine the boundaries of the economic efficiency of equipment. It is believed that only by economic criteria it is possible to identify the feasibility of implementing in any machine certain indicators of energy consumption, ecology, reliability, and safety. But, as a rule, there are many economic indicators and it is difficult to evaluate the equipment according to any single indicator.

It is known that the efficiency of tractors, combines and agricultural machines is assessed by numerous technological, operational and other indicators, and technologies by indicators of volume, quality, cost of production, etc. The following indicators of

*Corresponding author: dmitripet@mail.ru 
comparative economic efficiency are also used as criteria: annual savings in total cash costs, reduction in the cost of performing work, payback period, reduced need for maintenance personnel, reduced need for motor fuel, etc. Thus, equipment and technologies have a wide range of different parameters, which makes it difficult to determine their effectiveness by any one parameter. In addition, some technologies and machines will have some better indicators, while others will have others, so a dilemma arises, which technologies and technical means should be preferred?

In connection with the above, it becomes necessary to develop and apply a single methodology that will allow to evaluate technologies and equipment systematically for all available incomparable parameters, and in order to compare them with each other, they must be characterized using one generalized dimensionless quantitative indicator that takes into account the entire complex of indicators: technical, technological, economic, etc. in order to give an objective and unambiguous assessment. The generalized indicator, in which the main technical and operational indicators, etc. are reduced to a single measure and have uniform initial bases and content, facilitates the identification of the advantages of a technology or machine and their comprehensive assessment $[1,2]$.

The purpose of the study is to substantiate the use of nonparametric criteria in the comparative assessment of agricultural machinery and technologies with the development of a single method and software to identify the most effective options.

\section{Materials and methods}

The method of analysis of published results on the assessment of agricultural machinery and technologies using nonparametric criteria was used. Methods of hierarchical complex assessment of machines and technologies are applied using the rating scale proposed by P.U.Bakhtin and the corresponding desirability values according to E.S.Harrington $[3,5]$.

Calculations were carried out according to the program "Nonparametric choice" [6], designed for a comprehensive assessment of the functional indicators of a set of homogeneous objects (agricultural machinery, technologies, etc.), which allows to choose the most preferable option.

\section{Results and discussion}

In Kuban Scientific Research Institute for Testing Tractors and Agricultural Machines to determine the most effective technologies and machines using nonparametric criteria, a methodology for assessing the generalized indicator $w_{k}$, which is an integral criterion of particular indicators, determined by the formula, was proposed:

$$
w_{k}=\sum_{i=1}^{n} J_{i} \cdot a_{i}=J_{1} \cdot a_{1}+J_{2} \cdot a_{2} \ldots J_{n} \cdot a_{n}
$$

where $J_{i}$ - quantitative indices of change $i$ - indicators of a machine or technological process, which are defined as the ratio of the same type of indicators for the technological process performed by new and basic complexes of machines;

$n$ - number of estimated indicators;

$a_{i}$ - the weights of each estimate.

Weighting factors $a_{i}$ with a sufficient amount of experimental statistical material, they are established as a result of analysis of variance of the indicators. If there is not enough material, the weight coefficients can be determined by the method of expert assessment, in 
which questionnaires are drawn up, and specialists in this field assign the weight of each indicator in fractions of a unit or in percent.

In this case, the main problem is the difficulty of obtaining a representative sample of the opinions of experts competent in this area. Due to the small sample size, it is impossible to assess the stability of numerical series using traditional methods. Thus, in order to assess the stability of the opinions of experts, it is advisable to conduct a rank analysis of indicators, make a selection of sharply distinguished opinions, and then calculate the values of the weight coefficients. To do this, using the Spearman coefficient $r_{s}$ [7-9], the level of convergence of every two experts is assessed:

$$
r_{s}=1-\frac{6 \cdot \sum_{i=1}^{n} d_{i}^{2}}{n \cdot\left(n^{2}-1\right)}
$$

where $d$ - difference in rank of two experts;

$n$ - number of estimated indicators.

If during the assessment it is found that the agreement of some expert opinions is not great $\left(r_{s}<0,6 \ldots 0,7\right)$, then experts which $r_{s}$ indicator is the least, are removed from the list.

The final assessment of the consistency of opinions of experts is carried out using the Kendall coefficient of concordance $-W_{k}$ :

$$
W_{k}=\frac{12 \cdot \sum_{i=1}^{n} s_{i}}{m^{2}\left(n^{3}-n\right)}
$$

where $S_{i}$ - squared deviation of the sum of ranks from the mean;

$m$ - number of experts.

In its turn $S_{i}$ is found by the formula:

(4)

$$
S_{i}=\left(\sum_{i=1}^{m} X_{i j}-\bar{X}_{i j}\right)^{2}
$$

where $\bar{X}_{i j}$ - average value of the indicator rank over the entire array of opinions.

The average is calculated using the formula:

$$
\bar{X}_{i j}=\frac{1}{n} \cdot \sum_{i=1}^{m} \cdot X_{i j}
$$

Checking the significance of the coefficient of concordance $\left(W_{k}\right)$ is carried out according to Pearson's criterion $x^{2}$ with $(k-1)$ degrees of freedom.

With a high agreement of opinions, the value $W_{k}$ approaching the one. If it turns out that $W_{k} \leq 0,6 \ldots 0,7$, then it will be necessary to find again the values of the pair correlation coefficients $r_{s}$ and exclude from the list of specialists whose opinions will be the least.

As an example, we have defined the values of comparison indices $J_{i}$ "Table 1" and generalized indicator $w_{k}$ "Table 2" on various options for winter wheat cultivation technologies. To ensure the same estimated orientation in "Table 2", the yield index was inverted. 
Based on the conditions $w_{k}=\sum_{i=1}^{n} J_{i} \cdot a_{i} \rightarrow \min$ it was established, that the best is resource-saving technology (№ 4) of winter wheat cultivation $\left(w_{k}=0,66\right)$, technology (№ $2)$ is somewhat inferior to it, including new domestic equipment $\left(w_{k}=0,76\right)$.

Table 1. Index values $J_{i}$, of winter wheat cultivation and harvesting technologies indicators comparison

\begin{tabular}{|l|c|c|c|c|c|c|c|c|}
\hline \multirow{4}{*}{ Indicator name } & \multicolumn{6}{|c|}{ Indicator value by technology options } \\
\cline { 2 - 9 } & \multicolumn{2}{|c|}{ № 1 } & \multicolumn{2}{c|}{ № 2 } & \multicolumn{2}{c|}{ oo 3 } & \multicolumn{2}{c|}{ № 4 } \\
\cline { 2 - 9 } & $\begin{array}{c}\text { technology based } \\
\text { on the basic set } \\
\text { of machines }\end{array}$ & $\begin{array}{c}\text { technology based } \\
\text { on new domestic } \\
\text { machines }\end{array}$ & $\begin{array}{c}\text { technology } \\
\text { based on } \\
\text { foreign } \\
\text { machines }\end{array}$ & $\begin{array}{c}\text { resource-saving } \\
\text { technology based on } \\
\text { domestic machines }\end{array}$ \\
\cline { 2 - 9 } & units & $\boldsymbol{J}_{\boldsymbol{i}}$ & units & $\boldsymbol{J}_{\boldsymbol{i}}$ & units & $\boldsymbol{J}_{\boldsymbol{i}}$ & units & $\boldsymbol{J}_{\boldsymbol{i}}$ \\
\hline Productivity, c/ha & 40 & 1 & 50 & 1,25 & 60 & 1,50 & 50 & 1,25 \\
\hline Cost of grain, RUB/t & 1333 & 1 & 1159 & 0,87 & 1103 & 0,83 & 1055 & 0,79 \\
\hline Labor costs, man-h/t & 1,10 & 1 & 0,62 & 0,56 & 0,55 & 0,50 & 0,52 & 0,47 \\
\hline $\begin{array}{l}\text { Payback period of } \\
\text { capital investments, } \\
\text { years }\end{array}$ & 5,6 & 1 & 3,4 & 0,61 & 6,1 & 1,09 & 2,9 & 0,52 \\
\hline $\begin{array}{l}\text { The cost of a set of } \\
\text { machines, mln. RUB }\end{array}$ & 31,2 & 1 & 33,9 & 1,09 & 59,4 & 1,90 & 23,8 & 0,76 \\
\hline
\end{tabular}

Table 2. Reduced weights and generalized indicators of technology assessment

\begin{tabular}{|c|c|c|c|c|c|c|c|c|c|}
\hline \multirow{3}{*}{$\begin{array}{c}\text { Indicator } \\
\text { name }\end{array}$} & \multirow{3}{*}{$\begin{array}{c}\text { Weight } \\
\text { coeffici } \\
\text { ent }\end{array}$} & \multicolumn{8}{|c|}{ Indicator value by technology options } \\
\hline & & \multicolumn{2}{|r|}{ № 1} & \multicolumn{2}{|c|}{ № 2} & \multicolumn{2}{|r|}{ № 3} & \multicolumn{2}{|c|}{ № 4} \\
\hline & & $\overline{J_{i}}$ & $\begin{array}{c}\text { general } \\
\text { ized } \\
\text { weight }\end{array}$ & $J_{i}$ & $\begin{array}{c}\text { generali } \\
\text { zed } \\
\text { weight }\end{array}$ & $J_{i}$ & $\begin{array}{c}\text { generaliz } \\
\text { ed } \\
\text { weight }\end{array}$ & $\overline{J_{i}}$ & $\begin{array}{c}\text { generali } \\
\text { zed } \\
\text { weight }\end{array}$ \\
\hline Yield & 0,12 & $1 / 1$ & 0,12 & $\begin{array}{c}1 / 1,2 \\
5\end{array}$ & 0,10 & $1 / 1,5$ & 0,08 & $\begin{array}{c}1 / 1,2 \\
5\end{array}$ & 0,10 \\
\hline Cost of grain & 0,25 & 1 & 0,25 & 0,87 & 0,22 & $\begin{array}{c}0,8 \\
3\end{array}$ & 0,21 & $\begin{array}{c}0,7 \\
9\end{array}$ & 0,20 \\
\hline Labor costs & 0,10 & 1 & 0,10 & 0,56 & 0,06 & $\begin{array}{c}0,5 \\
0\end{array}$ & 0,05 & $\begin{array}{c}0,4 \\
7\end{array}$ & 0,05 \\
\hline $\begin{array}{l}\text { Payback } \\
\text { period }\end{array}$ & 0, & 1 & 0,40 & 0,61 & 0,24 & $\begin{array}{c}2,0 \\
9\end{array}$ & 0,44 & $\begin{array}{c}0,5 \\
2 \\
\end{array}$ & 0,21 \\
\hline Cost of MTP & 0,13 & 1 & 0,13 & 1,09 & 0,14 & $\begin{array}{c}0,9 \\
0\end{array}$ & 0,25 & $\begin{array}{c}0,7 \\
6\end{array}$ & 0,10 \\
\hline $\begin{array}{l}\text { Generalized } \\
\text { indicator }\end{array}$ & 1,0 & & 1,0 & & 0,76 & & 1,03 & & 0,66 \\
\hline
\end{tabular}

From the analysis of many works on the comprehensive assessment of machines and technologies of researchers: A.I. Lesnikovsky, G.G. Maslov, K.A. Sokhta, G.A.Zhidkov, etc., it was found that the most effective method is where, as a nonparametric criterion, another generalized evaluation criterion was applied (Harrington desirability function) [1014]. This method is based on the idea of converting the natural values of particular indicators (indicators of agrotechnical, operational and technological, economic assessments of machines and technologies, etc.) into a dimensionless scale of desirability. To obtain a scale of desirability, you can use a ready-made table of correspondences between preference relations in empirical and numerical systems. The value of a particular indicator, converted into a dimensionless scale of desirability, is denoted by $d_{j}(j=$ $1,2, \ldots, m)$ and is called private desirability. The desirability scale ranges from 0 to 1 . Value $d_{j}=0$ corresponds to the unacceptable level of this indicator, and value $d_{j}=1-$ to the 
highest value of the indicator. Value $d_{j}=0,37$ usually corresponds to the limit of acceptable values. Table 3 lists the standard desirability scale scores.

Table 3. Standard scores on a scale of desirability

\begin{tabular}{|l|l|}
\hline \multicolumn{1}{|c|}{ Desirability } & \multicolumn{1}{c|}{ Scale score } \\
\hline Excellent, represents high quality & $\begin{array}{l}0,80 \leq d_{j} \\
<1,00\end{array}$ \\
\hline Good, represents an improvement over acceptable & $\begin{array}{l}0,63 \leq d_{j} \\
<0,80\end{array}$ \\
\hline $\begin{array}{l}\text { Satisfactory, acceptable condition of the object, but low quality - improvement is } \\
\text { desirable }\end{array}$ & $\begin{array}{l}0,37 \leq d_{j} \\
<0,63\end{array}$ \\
\hline $\begin{array}{l}\text { Poor, unacceptable condition of the object, a noticeable improvement in quality is } \\
\text { required }\end{array}$ & $\begin{array}{l}0,20 \leq d_{j} \\
<0,37\end{array}$ \\
\hline Very bad, totally unacceptable quality of the object & $0 \leq d_{j}<0,20$ \\
\hline
\end{tabular}

The desirability function reflects the dependence of the desirability indicators $d_{j}$, from dimensionless indicators $y_{j}$, into which the dimensional (natural) indicators of the machine, technology is transferred. This dependence is expressed by the equation:

$$
d_{j}=\exp \left[-\exp \left(-y_{j}\right)\right]
$$

The generalized desirability index $\mathrm{D}$ is calculated by the formula:

(7)

$$
D=\sqrt[m]{\prod_{j=1}^{m} d_{j}}
$$

where $d_{j}$ - desirability value $j$ indicator;

$m$ - number of indicators.

For a quick comparative assessment of agricultural machinery and technologies and identify the most effective options at the Novokuban branch of Rosinformagrotech (Kuban Research Institute for Testing Tractors and Agricultural Machines) software "Nonparametric choice" was developed [6].

This program is intended for a comprehensive assessment of the functional indicators of many homogeneous objects (agricultural machinery, technologies, technological processes, the state of crops and soils, instruments and various equipment). The program uses a mathematical apparatus based on the generalized Harrington desirability function, which makes it possible to reduce all compared indicators using a nonparametric criterion (desirability indicator) to a single quantitative indicator in the form of a specific number, the value of which allows you to choose the most preferable option.

In accordance with the developed program "Nonparametric selection" and to determine the most effective seeding units, "Table 4" was formed based on the results of field research and a comprehensive processing of the results was carried out [15]. The results of the calculations of the seeding units are presented in "Table 5".

Table 4. Technical and operational indicators of seeding units 


\begin{tabular}{|l|c|c|c|c|c|}
\hline & $\begin{array}{c}\mathbf{8 3 2 0}+ \\
\text { Rapid } \\
\text { RD400C }\end{array}$ & $\begin{array}{c}\text { Rapid } \\
\text { RD400S }\end{array}$ & $\begin{array}{c}\text { Rapid } \\
\text { RDA800S }\end{array}$ & $\begin{array}{c}\text { 7730+ } \\
\text { Rapid } \\
\text { 400C }\end{array}$ & $\begin{array}{c}\text { Rapid } \\
\text { RD } \\
\text { 300C }\end{array}$ \\
\hline Hopper capacity, m ${ }^{3}$ & 4,2 & 4,0 & 3,3 & 4,2 & 3,0 \\
\hline Capture width, m & 4 & 4 & 8 & 4 & 3 \\
\hline Travel speed, km/h & 13,7 & 12,7 & 13,8 & 10,6 & 14,9 \\
\hline Changeable productivity, ha/h & 3,67 & 2,90 & 7,06 & 2,70 & 3,57 \\
\hline Fuel consumption, kg/ha & 4,20 & 7,23 & 4,50 & 8,30 & 6,60 \\
\hline Seeding compactness, \% & 97,1 & 81,6 & 90,0 & 85,7 & 80,0 \\
\hline
\end{tabular}

Table 5. Dimensionless, partial and generalized indicators for a comprehensive assessment of seeding units according to the program "Nonparametric choice"

\begin{tabular}{|c|c|c|c|c|c|c|c|c|c|c|}
\hline \multirow{3}{*}{ Indicator name } & \multicolumn{10}{|c|}{ Indicator value by aggregates } \\
\hline & \multicolumn{2}{|c|}{$\begin{array}{l}\text { JD 8320+ } \\
\text { Rapid } \\
\text { RD400C }\end{array}$} & \multicolumn{2}{|c|}{$\begin{array}{c}\text { Valtra 191+ } \\
\text { Rapid } \\
\text { RD400S }\end{array}$} & \multicolumn{2}{|c|}{$\begin{array}{c}\text { JD 9430+ } \\
\text { Rapid } \\
\text { RDA800S }\end{array}$} & \multicolumn{2}{|c|}{$\begin{array}{l}\text { JD 7730+ } \\
\text { Rapid 400C }\end{array}$} & \multicolumn{2}{|c|}{$\begin{array}{c}\text { Axion 830+ } \\
\text { Rapid RD } \\
\text { 300C }\end{array}$} \\
\hline & $y_{j}$ & $d_{j}$ & $y_{j}$ & $d_{j}$ & $y_{j}$ & $d_{j}$ & $y_{j}$ & $d_{j}$ & $y_{j}$ & $d_{j}$ \\
\hline Hopper capacity, $\mathrm{m}^{3}$ & 1,51 & 0,80 & 1,18 & 0,74 & 0,01 & 0,37 & 1,51 & 0,80 & - & 0,20 \\
\hline Capture width, m & 0 & 0,37 & 0 & 0,37 & 1,50 & 0,80 & 0 & 0,37 & $\overline{-}$ & 0,24 \\
\hline Travel speed, km/h & 0,67 & 0,60 & $\overline{-}$ & 0,36 & 0,67 & 0,60 & - & 0,01 & 1,48 & 0,80 \\
\hline $\begin{array}{l}\text { Changeable productivity, } \\
\text { ha/h }\end{array}$ & 0,06 & 0,39 & - & 0,27 & 1,51 & 0,80 & $\overline{-}$ & 0,24 & 0,01 & 0,37 \\
\hline Fuel consumption, kg/ha & 1,51 & 0,80 & $\overline{-}$ & 0,23 & 1,32 & 0,77 & $\overline{-}$ & 0,06 & 0,01 & 0,37 \\
\hline Seeding compactness, $\%$ & 1,35 & 0,77 & $\begin{array}{c}- \\
0,66\end{array}$ & 0,14 & 0,43 & 0,52 & $-\overline{13}$ & 0,32 & $\overline{-}$ & 0,09 \\
\hline $\begin{array}{l}\text { Generalized Desirability } \\
\text { Index, } D\end{array}$ & & 0,59 & & 0,32 & & 0,62 & & 0,15 & & 0,28 \\
\hline
\end{tabular}

Thus, the results of calculations using the software "Nonparametric selection" showed that the most efficient options are the JD 9430 + Rapid RDA800S and JD 8320 + Rapid $\mathrm{RD} 400 \mathrm{C}$ units, for which the generalized desirability indicators were 0.62 and 0.59 , respectively.

\section{Conclusions}

The above methodological approaches will make it possible to carry out a comprehensive assessment of the efficiency and competitiveness of agricultural machinery and technologies for a variety of essentially different indicators.

The presented methods can be used not only for a comparative assessment of individual machines, machine complexes in general, technologies for the production of agricultural crops, but also for the assessment of any other objects of research.

Using the program "Nonparametric choice", based on the Harrington desirability function, will make it possible to transfer particular indicators of the effectiveness of equipment, technologies, etc., different in physical essence and their dimensions, into a single dimensionless scale, and then collapse into a single generalized criterion by which one can quickly select the most effective option. 


\section{References}

1. V. O. Myroshnyk, A. O. Dudnyk, Optimization of efficiency of system management is with use of generalized function of desirability of harrington: Scientific Bulletin of NULES of Ukraine. Series: Engineering and energy of agro-industrial complex, (1962), 123-128 (2014)

2. C. Xiang, C. Jie, Optimization of the Impeller Geometry for an Automotive Torque Converter Using Response Surface Methodology and Desirability Function. Open Journal of Applied Sciences, 10(7), 455-475 (2020) doi: 10.4236 / ojapps.2020.107032.

3. Y. Adler, G. Stasova, Comparison between the Desirability Function by E.C. Harrington and the Loss Function by Genichi Taguchi, ANQ Congress 2012, Striving for excellence through Product and Service Quality (2012)

4. Y. Adler, G. Stasova, Statistical Approach for Decision Making (Based on Desirability Function by E. C. Harrington and the Loss Function by Genichi Taguchi), ANQ Congress 2013, Quality for the Strength of Asia (2013)

5. Yu. Adler, K. Stasova, Statistical approach for decision making: Communications in Dependability and Quality Management, 17(2), 5-15 (2014)

6. D. A. Petukhov, I. G. Popelova, Program "Non-parametric choice": witness. about the state. register. computer programs № 2016614893 from 11.05.2016.; Rus. Federation, applicant and copyright holder FSBSU "Rosinformagrotech"; declared № 2016612198 from 15.03.2016

7. W.-Y. Zhang, Z.-W. Wei, B.-H. Wang, X.-P. Han, Measuring mixing patterns in complex networks by spearman rank correlation coefficient: Physica A: Statistical Mechanics and its Applications, 451, 440-450 (2016)

8. L. Cheng, Z. Lu, L. Zhang, New spearman correlation based sensitivity index and its unscented transformation solutions: Journal of Engineering Mechanics - ASCE, 142(2), 1-9 (2016)

9. C. Xiao, J. Ye, C. Rong, R. M. Esteves, Using spearmans correlation coefficients for exploratory data analysis on big dataset: Concurrency Computation Practice and Experience, 28(14), 3866-3878 (2016)

10. L. A. Terskaya, I. A. Slesarchuk, Harrington desirability function for multi-attribute outdoor space quality assessment: IOP Conference Series: Materials Science and Engineering. International Science and Technology Conference "FarEastCon 2019", 082030 (2020)

11. M. Hatami, M. C. M.Cuijpers, M. D. Boot, Experimental Optimization of the Vanes Geometry for a Variable Geometry Turbocharger (VGT) Using a Design of Experiment (DoE) Approach. Energy Conversion and Management, 106, 1057-1070 (2015) doi.org/10.1016/j.enconman.2015.10.040

12. S. A. Atroshenko, I. A. Korolyov, N. Didenko, Evaluation of physico-mechanical properties of high-chromium tool steels modified with harrington method: Materials Physics and Mechanics, 26(1), 26-29 (2016)

13. Yu. Zharkov, Optimization of criteria for the work of conformity assessment bodies using the Harrington method. Standardization, certification, quality, 4, 36-38 (2004) 
14. V. F. Fedorenko, D. A. Petukhov, V. V. Serdyuk, Formation of structures of multifunctional cultivating and sowing units. Rural machinery and equipment, 5, 35-40 (2016)

15. S. N. Medvedko, G. A. Zhidkov, L. N. Shapovalova, Methodology for a comprehensive assessment of the efficiency of agricultural machines and technologies using the Harrington function. In the collection of scientific papers of the XII International Scientific and Practical Conference in the framework of the XXII Agroindustrial Forum of the South of Russia and the exhibition "Interagromash": State and prospects for the development of the agroindustrial complex. Don State Technical University, Agrarian Research Center "Donskoy", 774-777 (2019)

16. V. F. Fedorenko, D. A. Petukhov, I. G. Popelova, Information technologies in increasing the resource and energy efficiency of machine and tractor units. Rural machinery and equipment, 5, 18-22 (2016) 